\title{
EQUILÍBRIO ENTRE MULHERES E HOMENS NOS ÓRGÃOS DE GOVERNO DAS EMPRESAS COTADAS EM BOLSA A influência do compromisso estratégico empresarial
}

\author{
Nuno Paço \\ Socius - Centro de Investigação em Sociologia Económica e das Organizações / \\ CSG - Investigação em Ciências Sociais

\section{Sara Falcão Casaca} \\ ISEG - Lisbon School of Economics \& Management, Universidade de Lisboa \\ Socius - Centro de Investigação em Sociologia Económica e das Organizações / \\ CSG - Investigação em Ciências Sociais
}

\begin{abstract}
Resumo Este artigo apresenta os resultados de um estudo motivado pelo novo enquadramento normativo em vigor no país desde janeiro de 2018, que determina a obrigação de uma representação mínima de pessoas do sexo sub-representado nos cargos de administração e de fiscalização das entidades do setor público empresarial e das empresas cotadas em bolsa. A análise circunscreve-se a este último segmento empresarial. Conclui-se que, não obstante a possível coexistência de outros fatores igualmente facilitadores, existe uma correlação positiva entre um maior grau de compromisso estratégico empresarial no plano formal e uma representação mais equilibrada de mulheres e homens nos órgãos de governo das empresas cotadas em bolsa.
\end{abstract}

Palavras-chave: género, representação equilibrada, compromisso estratégico empresarial, empresas cotadas em bolsa.

\author{
Balance between women and men in the governing bodies of the listed companies: the \\ influence of the strategic business commitment
}

Abstract This article presents the results of a study motivated by the new regulatory framework in force in the country since January 2018, which determines the obligation of a minimum representation of people of the underrepresented sex in the management and supervisory positions of the public sector entities and of listed companies. The analysis is limited to the latter business segment. It is concluded that, despite the possible coexistence of other facilitating factors, there is a positive correlation between a greater degree of strategic business commitment at the formal level and a more balanced representation of women and men in the governing bodies of listed companies.

$\underline{\text { Keywords: }}$ gender, balanced representation, strategic business commitment, listed companies.

Équilibre entre les femmes et les hommes dans les organes directeurs des sociétés cotées en bourse: l'influence de l'engagement stratégique des entreprises

Résumé Cet article présente les résultats d'une étude motivée par le nouveau cadre réglementaire en vigueur dans le pays depuis janvier 2018, qui détermine l'exigence d'une représentation minimale des personnes du sexe sous-représenté aux postes de direction et l'inspection du secteur des entreprises publiques et des sociétés cotées en bourse. L'analyse se limite à ce dernier secteur commercial. Il est conclu que, malgré la coexistence éventuelle d'autres facteurs également facilitateurs, il existe une corrélation positive entre un degré plus élevé d'engagement stratégique des entreprises au niveau formel et une représentation plus équilibrée des femmes et des hommes dans les organes directeurs des sociétés cotées en bourse.

Mots clefs: genre, représentation équilibrée, engagement commercial stratégique, sociétés cotées. 
Equilibrio entre mujeres y hombres en los órganos de gobierno de las empresas que cotizan en bolsa: la influencia del compromiso comercial estratégico

Resumen Este artículo presenta los resultados de un estudio motivado por el nuevo marco regulatorio vigente en el país desde enero de 2018, que determina la obligación de una representación mínima de personas del sexo subrepresentado en los puestos de gestión y supervisión de las entidades del sector público y las empresas que cotizan en bolsa. El análisis se limita al último segmento de negocios. Se concluye que, a pesar de la posible coexistencia de "otros factores facilitadores", existe una correlación positiva entre un mayor grado de compromiso empresarial estratégico en términos formales y una representación más equilibrada de mujeres y hombres en los órganos de gobierno de las sociedades cotizadas.

Palabras clave: género, representación equilibrada, compromiso comercial estratégico, empresas cotizadas.

\section{Introdução}

A segregação sexual vertical, entendida como a sub-representação de mulheres em cargos superiores de gestão nas organizações, é um dos fenómenos mais resistentes à mudança (Casaca e Lortie, 2017). As causas são atribuídas a diversos fatores institucionais, culturais, estruturais e situacionais, compreendendo, por exemplo, os estereótipos de género, os papéis tradicionalmente associados aos homens e às mulheres e a inerente divisão sexual do trabalho, passando pelas estruturas e culturas organizacionais genderizadas (Acker, 1990; Connell, 2006; Dämmrich e Blossfeld, 2017; Longarela, 2017). A superação deste fenómeno, comummente designado por "teto de vidro", depende de um processo de mudança que vise a integração sistemática de uma perspetiva de igualdade entre mulheres e homens nas organizações (Casaca e Lortie, 2017). Esse processo deve envolver tanto a dimensão formal (e.g. orientações estratégicas e políticas organizacionais) como a informal (e.g. normas não formalizadas, representações e expetativas, rotinas de trabalho e interações sociais) (Ely e Meyerson, 2000). Este artigo centra-se na dimensão formal, apresentando os principais resultados de um estudo que procurou compreender a relação entre o compromisso estratégico empresarial com a igualdade de género e o equilíbrio entre mulheres e homens nos órgãos de governo das empresas cotadas em bolsa, em Portugal (Paço, 2019). Entende-se por compromisso estratégico aquele que as empresas inscrevem nos documentos utilizados para comunicar publicamente a respetiva estratégia.

Além de se tratar de um fenómeno ainda pouco estudado em Portugal, a pertinência do estudo ${ }^{1}$ decorre também do novo enquadramento normativo em vigor no país. A Lei n.. $62 / 2017$, em vigor desde 1 de janeiro de 2018, fixou a obrigatoriedade de uma representação mínima de pessoas do sexo sub-representado para os

1 Estudo integrado no projeto “Women on Boards: An Integrative Approach/ Mulheres nos Órgãos de Gestão das Empresas: uma Abordagem Integrada" (Refe PTDC/SOC-ASO/29895/2017), financiado pela Fundação para a Ciência e a Tecnologia e pelo Ministério da Ciência, Tecnologia e Ensino Superior (MCTES) através de fundos nacionais (PIDDAC) e desenvolvido no âmbito do Socius-CSG/ISEG-ULisboa. 
cargos de administração e de fiscalização das entidades do setor público empresarial e das empresas cotadas em bolsa. ${ }^{2}$

O artigo está estruturado de modo a rever, ainda que sinteticamente, os principais contributos sobre género, organizações e mudança organizacional, o enquadramento normativo nacional sobre equilíbrio entre mulheres e homens nos órgãos de governo das empresas, passando depois para a apresentação e discussão da análise empírica e dos respetivos resultados.

\section{Contributos teóricos para a compreensão do fenómeno de segregação sexual das organizações}

O conceito de segregação sexual vertical surgiu em finais da década de 70 do século XX (Hakim, 1979), procurando descrever o padrão de maior proporção de homens nos lugares de poder e de tomada de decisão nas organizações e de maior concentração de mulheres nos cargos e funções situados na base das hierarquias organizacionais (Longarela, 2017). A metáfora "teto de vidro" tem sido particularmente utilizada para descrever este fenómeno (Hymowitz e Schellhardt, 1986), procurando ilustrar a existência de obstáculos organizacionais invisíveis, não questionados e profundamente impregnados na cultura das organizações, que impedem a progressão profissional das mulheres e a sua nomeação ou promoção para as posições cimeiras na hierarquia das mesmas (Casaca e Lortie, 2017).

As causas da segregação sexual vertical são complexas e multifacetadas, sendo imputáveis a fatores institucionais, culturais, estruturais e situacionais. A investigação tem demonstrado que os países com melhores resultados na promoção do equilíbrio entre mulheres e homens nos lugares estratégicos das empresas são aqueles onde, no plano institucional, foi implementada legislação impulsionadora da mudança (vulgo "quotas"), prevendo sanções severas (hard sanctions) em caso de incumprimento (Humbert, Kelan e Clayton-Hathway, 2019). A existência de políticas públicas promotoras da igualdade entre mulheres e homens, incluindo de conciliação entre a vida profissional e a vida familiar, é amplamente reconhecida como um elemento igualmente facilitador da dessegregação sexual. Também do ponto de vista sociocultural, os contextos são mais favoráveis quando os valores e as práticas sociais se revelam consentâneos com a igualdade de papéis sociais entre mulheres e homens e a desconstrução de conceções estereotipadas sobre a masculinidade e a feminilidade (Humbert, Kelan e Clayton-Hathway, 2019; Seierstad et al., 2017; Wall e Amâncio, 2007). Nestes contextos, a situação das mulheres perante a educação/formação, a família e o mercado de trabalho é menos condicionada pela normatividade social que tem sustentado a divisão sexual do trabalho e a assimetria no plano do trabalho doméstico e relativo ao cuidar (Dämmrich e Blossfeld, 2017). A este respeito, importa ter presente que tanto as mulheres como os homens

2 A Lei n. ${ }^{\circ}$ 62/2017, de 1 de agosto, pode ser consultada em: https://dre.pt/home/-/dre/107791612/details/maximized (data de acesso: 18/02/2019). 
são, na sua individualidade e no plano situacional, influenciadas/os pela ordem de género, que se reflete nas suas identidades, nas opções e na forma como agem dentro e fora das organizações (Monteiro e Ferreira, 2013). Importa igualmente considerar os fatores estruturais inerentes ao funcionamento das organizações. Dada a sua importância no contexto deste artigo, dedicamos-lhe o subcapítulo seguinte.

\section{Da visão das organizações como espaços neutros do ponto de vista do género às abordagens sobre as organizações genderizadas}

Um dos trabalhos de referência acerca da sub-representação numérica em contextos organizacionais é o de Rosabeth Moss Kanter, que, em finais da década de 1970, procurou explicar as experiências negativas dessa condição, tanto nas interações e dinâmicas sociais como nas experiências vividas pelas pessoas pertencentes a grupos sub-representados (Kanter, 1977). Nos grupos "distorcidos" (skewed groups), em que existe uma preponderância de uma das categorias em função da outra (proporção aproximada de 85/15), as pessoas pertencentes à categoria social dominante tendem a controlar a dinâmica do grupo e a cultura prevalecente. Devido à existência de indivíduos que integram o grupo social minoritário (neste caso, as mulheres), é muito elevada a sua "visibilidade". Ocorre então o fenómeno de tokenism. A desproporcionalidade numérica exacerba a perceção da diferença e conduz, por exemplo, a uma maior pressão em termos de desempenho profissional. Pode também ter lugar a "polarização", que resulta da demarcação dos membros do grupo

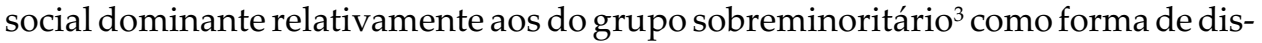
tanciamento em relação às suas supostas características e de reafirmação de alteridade (dinâmica que pode gerar a exclusão das pessoas do grupo expressivamente sub-representado). A autora refere como outras consequências o "aprisionamento de papéis" e a "assimilação", que advêm da distorção dos atributos genuínos e particulares de cada membro do grupo sub-representado, assumindo-se que detêm as características preconcebidas e socialmente atribuídas ao grupo social de pertença. Como consequência destes fenómenos, as mulheres-símbolo (tokens) estão sujeitas a uma maior pressão para a conformidade com a norma dominante, as conceções estereotipadas em função do género e as expetativas sociais.

Apesar de ter analisado a situação das mulheres em contexto de sobreminoria, Kanter (1977) considerou que o fenómeno de tokenism se verificaria de forma transversal sempre que, num dado contexto organizacional, um grupo social estivesse expressivamente sub-representado em relação ao grupo dominante. Esta abordagem, porém, viria a demonstrar-se insuficiente perante as evidências de que as experiências negativas inerentes a essa condição só se verificam em contextos onde são as mulheres o grupo minoritário; ao invés, quando estão os homens nessa condição, as experiências tendem a ser favoráveis e facilitadoras do reconhecimento e da ascensão profissional (Williams, 1992). Assim, a proporção numérica, por si 
só, é insuficiente para explicar as dinâmicas de grupo, as interações sociais e as experiências vividas pelas pessoas em situação de sobreminoria. A metáfora "escada rolante de vidro" simboliza a rápida progressão na carreira dos homens (Casaca e Lortie, 2017), revelando a importância da influência do género nas dinâmicas organizacionais, nos comportamentos dos grupos e nas relações interpessoais (Santos e Amâncio, 2014).

Na década de 1990, surgiu um dos mais importantes contributos para o debate científico: o entendimento de que as organizações são genderizadas. O género está incrustado nas estruturas sociais e nas organizações de trabalho, moldando as oportunidades, condições e trajetórias de vida dos indivíduos (Acker, 1990; Cockburn, 1983; Connell, 2006; Martin e Collinson, 2002). Numa publicação de referência, Acker (1990) veio sublinhar que as organizações, embora tradicionalmente teorizadas como sendo neutras têm incrustada a "marca" do género nas suas estruturas, políticas, normas e processos organizacionais e de gestão, nas práticas e nas interações sociais. Ao longo dos tempos, as organizações foram maioritariamente conceptualizadas, desenhadas e controladas por homens, pelo que as características tradicionalmente associadas aos mesmos tendem a ser as mais valorizadas: "o trabalhador neutro que ocupa o posto de trabalho abstrato é [na verdade] um trabalhador do sexo masculino, cuja vida está centrada no seu emprego a tempo inteiro, ao longo da vida, enquanto a sua mulher assegura as suas necessidades pessoais e as suas crianças" (adaptado de Acker, 1990: 149).

Ao invés da visão de que as organizações são neutras, o debate teórico tem evoluído no sentido de reconhecer que as organizações são "regimes de género" que refletem a ordem de género mais vasta, estando impregnadas das representações sociais dominantes acerca da masculinidade e da feminilidade, dos papéis sociais das mulheres e dos homens e da sobrevalorização conferida aos atributos tidos como masculinos em detrimento dos femininos (Connell, 2006). Além disso, as organizações passaram igualmente a ser concebidas como "fábricas de género" - contextos dinâmicos onde, a partir de ações individuais e coletivas, são criadas, reproduzidas (ou desconstruídas) as representações simbólicas em torno do género e a divisão sexual do trabalho (Calás, Smircich e Holvino, 2014).

A literatura sobre a gestão da mudança organizacional não tem, em geral, integrado uma perspetiva de género (Casaca e Lortie, 2017). Seguindo o raciocínio de Ely e Meyerson (2000), para que a mudança promova a igualdade de género devem estar integradas no planeamento e na intervenção quatro categorias organizacionais: (1) estratégia, políticas e procedimentos formais; (2) narrativas, retóricas, linguagem e outras expressões simbólicas; (3) normas, padrões de trabalho e práticas de trabalho; (4) padrões informais de interação social quotidiana.

De acordo com Steensen (2014), a estratégia organizacional reflete as intenções da organização e pode ser declarada por via de documentos formais, isto é, planos, relatórios e políticas organizacionais expressamente formuladas. Com efeito, a integração do compromisso com a igualdade de género na estratégia organizacional, declarada através destes documentos, pode ser entendida como uma intenção formalmente explicitada de promover essa igualdade e enquadra-se na primeira categoria anteriormente definida (Ely e Meyerson, 2000). Em Portugal, os 
poucos estudos realizados têm também incorporado a importância do compromisso formal com a promoção da igualdade entre mulheres e homens nas organizações (Casaca et al., 2016; CITE, 2008; Guerreiro, Lourenço e Pereira, 2006; Monteiro e Ferreira, 2013; Pernas, Fernandes e Guerreiro, 2008).

De acordo com Eriksson-Zetterquist e Renemark (2016), as mudanças que visam a promoção da igualdade de género nas organizações possuem uma taxa de insucesso elevada. Esse insucesso deve-se ao facto de as organizações realizarem alterações nas suas estruturas formais, comprometendo-se, por exemplo, com a igualdade de género ao nível estratégico, sem que tal produza mudanças efetivas nos processos internos de gestão, nos padrões informais de organização do trabalho, nas expetativas e interações sociais. Muitas organizações procuram seguir os temas que se apresentam na "moda", recorrendo a alterações nas suas políticas formais e até nas suas estruturas internas com o objetivo de espelhar a fidelidade a essas novas tendências na sua imagem externa. No entanto, muitas tendem a descuidar a importância de gerar e institucionalizar alterações na cultura informal da organização, deixando por questionar e rever a dimensão genderizada da mesma. Ainda assim, as mudanças formais constituem sempre uma oportunidade para que sejam realizadas ações reais nesse sentido.

\section{A evidência estatística como fundamento da adoção de medidas legislativas de natureza vinculativa}

A Lei n.. 62/2017, que entrou em vigor no dia 1 de janeiro de 2018, veio estabelecer a obrigatoriedade de adoção de um regime de representação equilibrada entre homens e mulheres nos órgãos de administração e fiscalização das empresas cotadas em bolsa e das entidades do setor público empresarial. Este novo regime legal prevê o estabelecimento de uma representação mínima do sexo sub-representado nos órgãos de governo das empresas-alvo. No que diz respeito às empresas cotadas em bolsa, a lei determina que "a proporção de pessoas de cada sexo designadas de novo para cada órgão de administração e de fiscalização de cada empresa não pode ser inferior a $20 \%$, a partir da primeira assembleia geral eletiva após 1 de janeiro de 2018 , e a 33,3\%, a partir da primeira assembleia geral eletiva após 1 de janeiro de 2020". A lei prevê sanções em casos de incumprimento dos limiares mínimos definidos . Estabelece ainda a obrigatoriedade da adoção de planos para a igualdade (de género) pelas empresas vinculadas, assim como a sua publicação nos respetivos sítios da internet.

Este novo quadro normativo teve como fundamentação a evidência estatística da baixa representação de mulheres na liderança das empresas, em particular nas cotadas em bolsa, além do fraco efeito das medidas de política pública tipificadas como soft e dos incentivos à autorregulação (Casaca, 2017). Com efeito, apesar da participação elevada das mulheres no mercado de trabalho e da sobre-escolarização em relação aos homens, a realidade laboral portuguesa continua a caracterizar-se pela existência de profundas desigualdades entre homens e mulheres (Coelho e Ferreira, 2018; Torres et al., 2018). O fenómeno de segregação sexual vertical é, por conseguinte, uma 
EQUILÍBRIO ENTRE MULHERES E HOMENS NOS ÓRGÃOS DE GOVERNODAS EMPRESAS COTADAS EM BOLSA 81

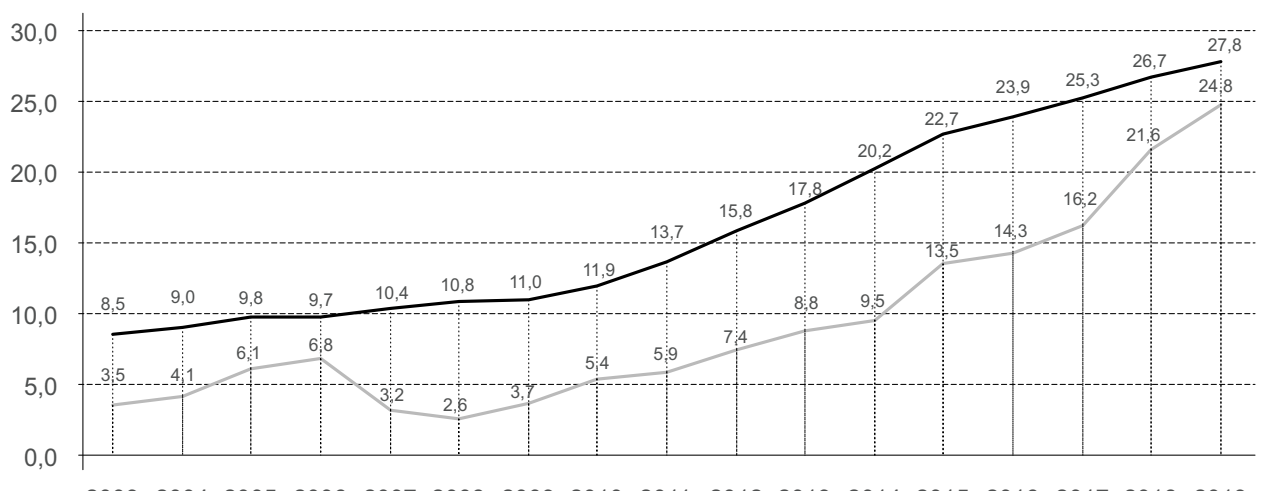

20032004200520062007200820092010201120122013201420152016201720182019

$$
\text { - EU28 - Portugal }
$$

Figura 1 Evolução da representação de mulheres nos órgãos de administração das maiores empresas cotadas em bolsa em Portugal (\%) (2003-2019)

Fonte: EIGE (2019) [em linha]. Decision-Making Database, disponível em:

https://eige.europa.eu/gender-statistics/dgs/indicator/wmidm_bus_bus_wmid_comp_compbm/line (consultado em 30/07/2019).

das manifestações mais persistentes dessas assimetrias (Casaca, 2015, 2017; EIGE, 2019).

A adoção de recomendações soft (não vinculativas) e de incentivos a um maior equilíbrio de género nos órgãos de governo das empresas cotadas em bolsa em Portugal teve lugar em 2012 (Casaca, 2017). A figura 1 demonstra que, após uma representação de mulheres praticamente nula nos conselhos de administração das maiores empresas cotadas em bolsa (3,5 por cento, em 2003), ${ }^{4}$ houve um aumento de 4 pontos percentuais entre 2014 e 2015. O valor foi progredindo ligeiramente, mas manteve-se a distância em relação à média da União Europeia. Assim, à data de aprovação da Lei n.. $62 / 2017$, o valor relativo à percentagem de mulheres nos órgãos de decisão daquele segmento de empresas não era animador, fixando-se em 16,2 por cento, menos 9,1 pontos percentuais que a média da UE28. Em 2018, este valor subiu para 21,6 por cento, coincidindo com a entrada em vigor da lei. Ainda assim, atualmente Portugal apresenta um valor abaixo da média da UE (EIGE, 2019).

De acordo com os últimos dados disponíveis, a percentagem média de mulheres nos conselhos de administração das maiores empresas cotadas em bolsa na União Europeia é ainda muito inferior ao limiar mínimo de paridade (40\%)

4 Não existem dados disponíveis para os anos anteriores. Os dados disponibilizados pelo EIGE (European Institute for Gender Equality), Decision-Making Database, reportam-se apenas aos conselhos de administração das maiores empresas cotadas em bolsa. 
(Conselho da Europa, 2003). Apenas em França (um dos primeiros países da UE a implementar medidas legislativas vinculativas, em 2011) o valor (44\%) supera esse limiar. É nos países onde existe legislação vinculativa que o desequilíbrio numérico entre homens e mulheres mais tem sido contrariado (Humbert, Kelan e Clayton-Hathway, 2019).

\section{Opções metodológicas}

Para a análise efetuada procurou-se recolher os documentos estratégicos das 42 empresas cotadas em bolsa (universo) relativos ao ano de 2017, de forma a observar em que medida o compromisso estratégico empresarial com a igualdade de género já estava plasmado nos mesmos antes da entrada em vigor da Lei n. ${ }^{-}$ $62 / 2017$. A pesquisa recaiu sobre os websites das respetivas empresas. Foram reunidos dois tipos de documentos públicos considerados estratégicos: os relatórios de sustentabilidade e os códigos de ética. De acordo com McKay (2017) e Rosati e Faria (2019), a sustentabilidade (empresarial) resulta na gestão dos impactos ao nível social, ambiental e económico por parte das organizações e encontra-se articulada com a estratégia organizacional. Por este motivo, os relatórios de sustentabilidade foram classificados como documentos estratégicos. A mesma classificação recaiu sobre os códigos de ética, uma vez que é através dos mesmos que as organizações divulgam os seus princípios éticos e valores, assim como as responsabilidades que detêm perante os seus stakeholders. Acresce que tais documentos são frequentemente utilizados para guiar os comportamentos dos/as trabalhadores/as e reforçar a imagem pública das organizações (Stevens, 2009).

Do universo contemplado no estudo, apenas em 18 empresas os relatórios de sustentabilidade estavam disponíveis nos respetivos websites, e em 19 empresas foi possível recolher os códigos de ética. Destas, 12 empresas disponibilizavam ambos os documentos. Procedeu-se a uma análise qualitativa do conteúdo textual dos documentos reunidos, com recurso ao software MAXQDA.

Num segundo momento, a análise quantitativa recaiu sobre as 18 empresas com os respetivos relatórios de sustentabilidade divulgados nos websites, uma vez que se concluiu que os códigos de ética apenas reproduziam as menções já contempladas nos relatórios de sustentabilidade, de forma muito abreviada e apenas referente a uma categoria analítica ("compromisso com a não discriminação e igualdade de oportunidades"). Esta análise compreende, assim, $43 \%$ do universo das empresas cotadas em bolsa em 2017. Ainda nesta fase, e para as mesmas empresas, foram recolhidos os relatórios de contas, de forma a obter informação sobre a representação de mulheres e de homens que integram os respetivos órgãos de governo. A análise foi desenvolvida com o objetivo de testar a hipótese de que existe uma correlação positiva entre um maior compromisso estratégico empresarial com a igualdade entre mulheres e homens e uma representação mais equilibrada de mulheres e homens nos órgãos de governo nas empresas cotadas em bolsa em Portugal. Foi então efetuada uma análise de correlação através do cálculo do coeficiente Rho de Spearman. 
Procurou-se que as duas variáveis consideradas para a análise de correlação refletissem as duas dimensões em estudo: (1) "grau de compromisso estratégico empresarial com a igualdade entre mulheres e homens das empresas cotadas em bolsa em Portugal" e (2) "grau de representação equilibrada de mulheres e homens nos órgãos de governo nas empresas cotadas em bolsa em Portugal".

A variável correspondente à dimensão (1) foi desenvolvida com base em informações provenientes da análise qualitativa, onde foi dado destaque ao compromisso com a igualdade entre mulheres e homens nos documentos estratégicos das empresas cotadas em bolsa. A partir destas informações, foi possível criar uma variável ordinal, que varia entre 1 e 6 , denominada "índice de compromisso com a igualdade entre mulheres e homens nos documentos estratégicos empresariais das empresas cotadas em bolsa em Portugal". Relativamente à dimensão (2), considerou-se a "percentagem de mulheres nos órgãos de governo das empresas cotadas em bolsa em Portugal". Esta variável foi tratada como ordinal (menos de 5\%; $6-10 \% ; 11-15 \% ; 16-20 \% ; 21-25 \% ; 26-30 \% ; 31-35 \% ; 36-40 \% ; 41-45 \% ; 46-50 \%$ ) (consultar anexo 1).

\section{Análise e discussão dos resultados: o compromisso estratégico empresarial com a igualdade e o equilíbrio entre mulheres e homens nos órgãos de governo das empresas}

Da análise de conteúdo textual aos dois documentos estratégicos das empresas cotadas em bolsa resultaram seis categorias, associadas a uma quantidade variável de excertos ${ }^{5}$ (representada pela dimensão das circunferências na figura 2).

Como referido, verifica-se que o compromisso com a igualdade entre mulheres e homens se encontra maioritariamente presente nos relatórios de sustentabilidade, onde foram identificados excertos relativos às seis categorias que resultaram da análise. No que diz respeito aos códigos de ética, apenas foram identificados excertos relativos ao "compromisso com a não discriminação e igualdade de oportunidades".

Do total de documentos analisados, relativos às 18 empresas que constituem a amostra, apenas cinco não integravam qualquer tipo de compromisso com a igualdade entre mulheres e homens.

Tal como ilustra a figura 2, foram identificados sete excertos em quatro documentos relativos à categoria "acordos com mecanismos oficiais para a igualdade de género". Relativamente a esta categoria, de um modo geral o "iGen - Fórum Organizações para a Igualdade" 6 e o "Compromisso com o Governo de Portugal"7 foram

5 Alguns excertos foram identificados como pertencentes a mais do que uma categoria.

6 Missão do iGen - Fórum Organizações para a Igualdade pode ser consultada em: http://forumigen.cite.gov.pt/forum-igen/ (data de acesso: 17/07/2019).

7 Em 2015, 13 das 43 empresas cotadas em bolsa assinaram um compromisso com o governo de Portugal no sentido de atingirem os limiares mínimos de representação de cada sexo nos seus órgãos de gestão. 


\begin{tabular}{|c|c|c|}
\hline Lista de códigos & $\begin{array}{c}\text { Relatórios } \\
\text { de sustentabilidade }\end{array}$ & $\begin{array}{l}\text { Códigos } \\
\text { de ética }\end{array}$ \\
\hline Acordos com mecanismos oficiais para a igualdade de género . & $\bullet$ & \\
\hline Compromisso com a não discriminação e igualdade de oportunidade & C. & \\
\hline Explicitação do comp. com a rep. equilibrada de $\mathrm{M} \mathrm{e} \mathrm{H} \mathrm{nos} \mathrm{OG}$ & $\bullet$ & \\
\hline Intenção explicitada de adoção/existência de um PI. & $\bullet$ & \\
\hline Políticas e práticas de promoção para a igualdade de género. & . & \\
\hline Reconhecimento público do compromisso com a igualdade de género & •. & \\
\hline
\end{tabular}

Figura 2 Matriz de categorias (MAXQDA)

Nota: OG — órgãos de gestão; PI — planos para a igualdade; $\mathrm{M}$ - mulheres; $\mathrm{H}$ - homens.

os acordos mais referenciados. Em segundo lugar, para a categoria "compromisso com a não discriminação e igualdade de oportunidades" foram identificados 38 excertos num total de 22 documentos, 15 excertos em relatórios de sustentabilidade e 23 em códigos de ética. Esta foi, aliás, a categoria com o maior número de excertos observados. De um modo geral, os excertos que se referem à não discriminação e igualdade de oportunidades refletem os termos expressos na Constituição da República Portuguesa e na Declaração Universal dos Direitos Humanos.

Em relação à categoria "explicitação do compromisso com a representação equilibrada de mulheres e homens nos órgãos de governo das empresas", foram identificados oito excertos em cinco documentos. A existência desta categoria sugere que há um reconhecimento do fenómeno da segregação sexual vertical por parte das empresas, assim como um compromisso formal com a superação do mesmo.

Para a categoria "intenção explicitada de adoção/existência de um plano para a igualdade", foram identificados quatro excertos em dois documentos. Foram ainda observadas referências à existência de planos para a igualdade e, num caso específico, à intenção de elaboração de um plano para a igualdade no futuro.

No que diz respeito à categoria "políticas e práticas de promoção para a igualdade de género", foram identificados 11 excertos em oito documentos. Nesta categoria, verifica-se que as políticas e práticas referenciadas se encontram, em geral, relacionadas com processos de gestão de recursos humanos e, tendem a ser apresentadas de forma relativamente vaga e pouco pormenorizada.

Por último, no que se refere à categoria "reconhecimento público do compromisso com a igualdade de género", que se reportava a prémios ou menções honrosas, foram identificados apenas três excertos em apenas um documento. Trata-se da categoria com o menor número de excertos identificados.

É possível concluir que o compromisso com a igualdade de género se encontra expresso nos relatórios de sustentabilidade de forma relativamente autonomizada e variada; no entanto, o mesmo não acontece com os códigos de ética, onde esta dimensão é apenas referenciada na ótica dos direitos fundamentais. 


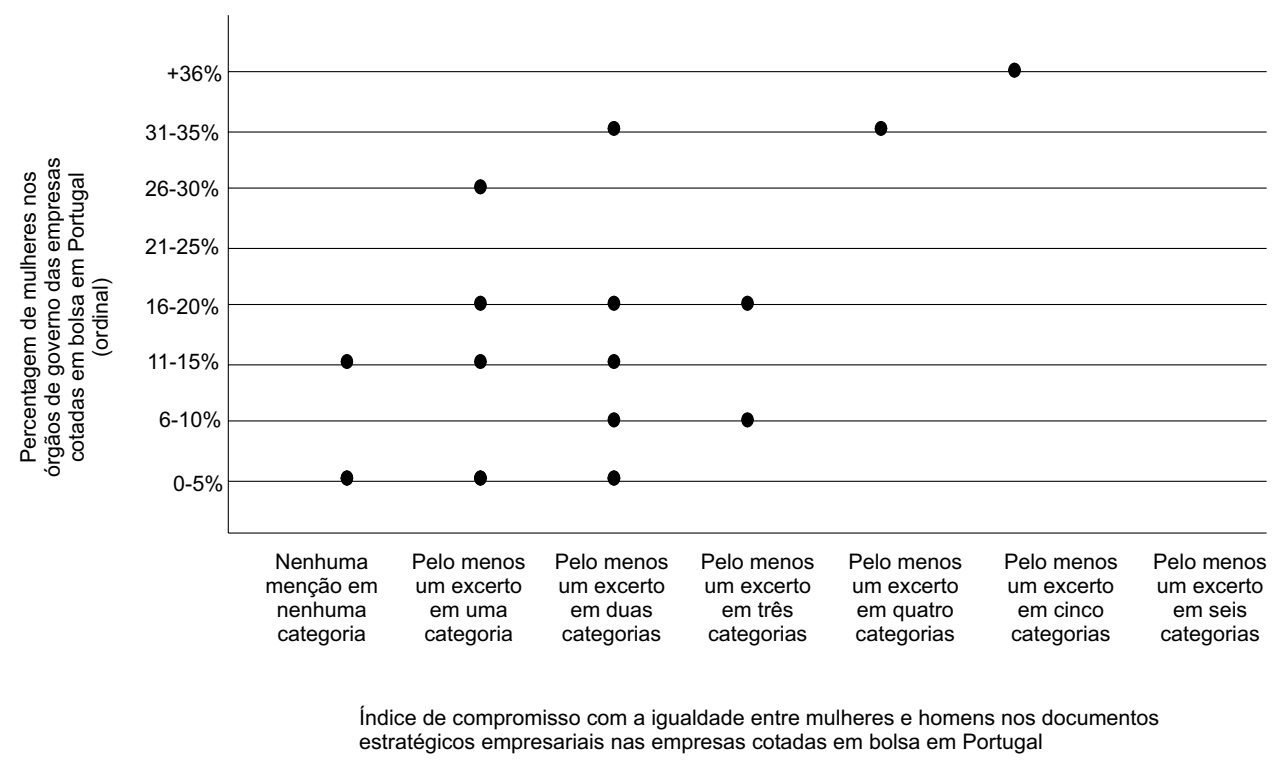

Figura 3 Relação entre "índice de compromisso com a igualdade entre mulheres e homens nos documentos estratégicos empresariais nas empresas cotadas em bolsa em Portugal" e "percentagem de mulheres nos órgãos de governo das empresas cotadas em bolsa em Portugal"

Esse compromisso está sobretudo expresso nas seguintes seis categorias: “acordos com mecanismos oficiais para a igualdade de género", "compromisso com a não discriminação e igualdade de oportunidades", "explicitação do compromisso com a representação equilibrada de mulheres e homens nos órgãos de governo das empresas", "intenção explicitada de adoção/existência de um plano para a igualdade", "políticas e práticas de promoção para a igualdade de género" e "reconhecimento público do compromisso com a igualdade de género".

Procurou-se depois testar a hipótese de que existe uma correlação positiva entre um maior compromisso estratégico empresarial com a igualdade entre mulheres e homens e uma representação mais equilibrada de mulheres e homens nos órgãos de governo nas empresas cotadas em bolsa em Portugal. Para tal, procedeu-se à análise da correlação entre as variáveis "índice de compromisso com a igualdade entre mulheres e homens nos documentos estratégicos empresariais nas empresas cotadas em bolsa em Portugal" e "percentagem de mulheres nos órgãos de governo das empresas cotadas em bolsa em Portugal". Tendo o gráfico de dispersão sugerido que as duas variáveis se correlacionam positivamente (figura 3), procedeu-se ao cálculo do coeficiente correlação Rho de Spearman.

Verifica-se, pois, que as variáveis "índice de compromisso com a igualdade entre mulheres e homens nos documentos estratégicos empresariais nas empresas cotadas em bolsa em Portugal" e "percentagem de mulheres nos órgãos de governo 
das empresas cotadas em bolsa em Portugal" estão positiva e moderadamente correlacionadas, ${ }^{8} \mathrm{e}$ de forma significativa $r_{\mathrm{s}}=0,49, p=0,041$. A análise sugere que as empresas que já manifestavam formalmente um maior grau de compromisso com a igualdade entre mulheres e homens, quando a Lei n. ${ }^{\circ}$ 62/2017 foi aprovada, estão mais próximas do cumprimento dos termos da mesma quanto a uma representação mais equilibrada de mulheres e homens nos respetivos órgãos de governo. Logo, o compromisso estratégico empresarial com a igualdade entre mulheres e homens pode ser considerado um antecedente organizacional facilitador da efetividade da Lei.

\section{Conclusão}

O estudo que sustenta este artigo foi motivado pelo novo enquadramento normativo em vigor no país, desde janeiro de 2018, que determina uma representação mais equilibrada de mulheres e homens nos cargos de administração e de fiscalização das entidades do setor público empresarial e das empresas cotadas em bolsa. A análise recaiu sobre este último segmento empresarial e procurou compreender se o compromisso estratégico empresarial com a igualdade entre mulheres e homens, expresso previamente (em 2017), pode ser um antecedente organizacional facilitador da efetividade da lei.

De acordo com a informação obtida a partir da análise qualitativa, conclui-se que o compromisso com a igualdade entre mulheres e homens está explicitado nos documentos estratégicos da maioria das empresas cotadas em bolsa que integram a amostra. Sucede fundamentalmente nos respetivos relatórios de sustentabilidade de forma relativamente autonomizada e variada. Os sentidos que assume correspondem a seis categorias identificadas: "acordos com mecanismos oficiais para a igualdade de género", "compromisso com a não discriminação e igualdade de oportunidades", "explicitação do compromisso com a representação equilibrada de mulheres e homens nos órgãos de governo das empresas", "intenção explicitada de adoção/existência de um plano para a igualdade", "políticas e práticas de promoção para a igualdade de género" e "reconhecimento público do compromisso com a igualdade de género".

A análise quantitativa permitiu correlacionar o grau de compromisso estratégico empresarial com a igualdade entre mulheres e homens com o grau de representação equilibrada de mulheres e homens nos órgãos de governo nas empresas cotadas e bolsa em Portugal. A este propósito, considerando os critérios definidos na análise quantitativa, conclui-se que as duas dimensões estão positiva e moderadamente correlacionadas entre si: nas empresas cotadas em bolsa em Portugal, quanto maior (e mais variado) é o compromisso estratégico empresarial com a igualdade entre mulheres e homens, mais equilibrada é a representação de mulheres e homens nos respetivos órgãos de governo.

8 Recorde-se que $r_{\mathrm{s}}=0$ equivaleria a ausência de correlação e 1 a correlação perfeita. 
A análise efetuada sugere que o compromisso estratégico empresarial com a igualdade entre mulheres e homens é relevante para que seja alcançada uma representação mais equilibrada de mulheres e homens nos órgãos de governo das empresas. O compromisso estratégico com a igualdade de género constitui-se, portanto, como um antecedente organizacional facilitador do cumprimento da Lei n.. $62 / 2017$ por parte das empresas vinculadas.

Há um amplo consenso na literatura de que a implementação de medidas que visem a promoção da igualdade entre mulheres e homens nas organizações exige a realização de um processo de mudança planeado, integrado e sistémico (Casaca e Lortie, 2017; Eriksson-Zetterquist e Renemark, 2016), que extravase o mero compromisso formal com a igualdade de género e desafie as estruturas e as culturas organizacionais genderizadas.

Não é possível, a partir do estudo, deduzir que as organizações que integram a igualdade de género nas suas políticas formais, no plano da retórica, incorporem efetivamente essa igualdade ao nível das práticas, dos processos internos de gestão, dos padrões informais de trabalho e de interação social. No entanto, os compromissos formais e publicamente assumidos constituem uma oportunidade para que sejam realizadas ações concretas de mudança organizacional. Este estudo evidencia a relevância do aprofundamento da investigação sobre a gestão da mudança organizacional orientada para a promoção da igualdade entre mulheres e homens. 
Anexo 1 Guião de variáveis da análise quantitativa

\begin{tabular}{|c|c|c|c|}
\hline Dimensão & Variáveis & Escala & Fontes \\
\hline $\begin{array}{l}\text { Grau de representação } \\
\text { equilibrada de mulheres e } \\
\text { homens nos órgãos de } \\
\text { governo nas empresas } \\
\text { cotadas em bolsa em } \\
\text { Portugal }\end{array}$ & $\begin{array}{l}\text { Percentagem de mulheres nos } \\
\text { órgãos de governo das } \\
\text { empresas cotadas em bolsa } \\
\text { em Portugal }\end{array}$ & Variável ordinal & $\begin{array}{l}\text { Relatórios de } \\
\text { contas anuais }\end{array}$ \\
\hline \multirow{7}{*}{$\begin{array}{l}\text { Grau de compromisso } \\
\text { estratégico empresarial } \\
\text { com a igualdade entre } \\
\text { mulheres e homens nas } \\
\text { empresas cotadas em } \\
\text { bolsa em Portugal }\end{array}$} & $\begin{array}{l}\text { Possui pelo menos um excerto } \\
\text { sobre "Acordos com } \\
\text { mecanismos oficiais para a } \\
\text { igualdade de género" }\end{array}$ & $\begin{array}{l}\text { Variável nominal } \\
\text { (1=sim; } 2=\text { não) }\end{array}$ & $\begin{array}{l}\text { Relatórios de } \\
\text { sustentabilidade }\end{array}$ \\
\hline & $\begin{array}{l}\text { Possui pelo menos um excerto } \\
\text { sobre um "Compromisso com a } \\
\text { não discriminação e igualdade } \\
\text { de oportunidades" }\end{array}$ & $\begin{array}{l}\text { Variável nominal } \\
(1=\operatorname{sim} ; 2=\text { são) }\end{array}$ & $\begin{array}{l}\text { Relatórios de } \\
\text { sustentabilidade }\end{array}$ \\
\hline & $\begin{array}{l}\text { Possui pelo menos um excerto } \\
\text { sobre uma "Explicitação do } \\
\text { compromisso com a } \\
\text { representação equilibrada de } \\
\text { mulheres e homens nos órgãos } \\
\text { de governo das empresas" }\end{array}$ & $\begin{array}{l}\text { Variável nominal } \\
\text { (1=sim; } 2=\text { não) }\end{array}$ & $\begin{array}{l}\text { Relatórios de } \\
\text { sustentabilidade }\end{array}$ \\
\hline & $\begin{array}{l}\text { Possui pelo menos um excerto } \\
\text { sobre uma "Intenção } \\
\text { explicitada de } \\
\text { adoção/existência de um plano } \\
\text { para a igualdade" }\end{array}$ & $\begin{array}{l}\text { Variável nominal } \\
(1=\operatorname{sim} ; 2=\text { não) }\end{array}$ & $\begin{array}{l}\text { Relatórios de } \\
\text { sustentabilidade }\end{array}$ \\
\hline & $\begin{array}{l}\text { Possui pelo menos um excerto } \\
\text { sobre "Políticas e práticas de } \\
\text { promoção para a igualdade de } \\
\text { género" }\end{array}$ & $\begin{array}{l}\text { Variável nominal } \\
(1=\operatorname{sim} ; 2=\text { não) }\end{array}$ & $\begin{array}{l}\text { Relatórios de } \\
\text { sustentabilidade }\end{array}$ \\
\hline & $\begin{array}{l}\text { Possui pelo menos um excerto } \\
\text { sobre um "Reconhecimento } \\
\text { público do compromisso com a } \\
\text { igualdade de género" }\end{array}$ & $\begin{array}{l}\text { Variável nominal } \\
\text { (1=sim; } 2=\text { não) }\end{array}$ & $\begin{array}{l}\text { Relatórios de } \\
\text { sustentabilidade }\end{array}$ \\
\hline & $\begin{array}{l}\text { Índice de compromisso com a } \\
\text { igualdade entre mulheres e } \\
\text { homens nos documentos } \\
\text { estratégicos empresariais nas } \\
\text { empresas cotadas em bolsa } \\
\text { em Portugal }\end{array}$ & $\begin{array}{l}\text { Variável ordinal } \\
1=\text { pelo menos um excerto em } \\
\text { uma categoria; } \\
2=\text { =elo menos um excerto em } \\
\text { duas categorias; } \\
3=\text { pelo menos um excerto em } \\
\text { três categorias; } \\
4=\text { pelo menos um excerto em } \\
\text { quatro categorias; } \\
5=\text { pelo menos um excerto em } \\
\text { cinco categorias; } \\
6=\text { pelo menos um excerto em } \\
\text { seis categorias. }\end{array}$ & Índice sintético \\
\hline
\end{tabular}




\section{Referências bibliográficas}

Acker, Joan (1990), “Hierarchies, jobs, bodies: a theory of gendered organizations", Gender \& Society, 4 (2), pp. 139-158.

Calás, Marta B., Linda Smircich, e Evangelina Holvino (2014), “Theorizing gender-and-organization: changing times... changing theories", em Savita Kumra, Ruth Simpson e Ronald J. Burke (orgs.), The Oxford Handbook of Gender in Organizations, Oxford, Oxford University Press, pp. 17-52.

Casaca, Sara Falcão (2015), “A igualdade entre mulheres e homens e a tomada de decisão na esfera económica: o longo percurso do enquadramento político e dos instrumentos normativos", Revista de Estudos Demográficos, 56, pp. 5-23.

Casaca, Sara Falcão (2017), "Portugal: the slow progress of the regulatory framework", em Cathrine Seierstad, Patricia Gabaldon, e Heike Mensi-Klarbach (orgs.), Gender Diversity in the Boardroom, Londres, Palgrave Macmillan, pp. 45-74.

Casaca, Sara Falcão (coord.), Heloísa Perista, Anália Torres, Patrícia São João, Catarina Correia, e Eudelina Quintal (2016), Guia para a Promoção da Igualdade entre Mulheres e Homens, Lisboa, ISEG-ULisboa, CESIS, ISCPS-ULisboa, EEAGrants-CIG.

Casaca, Sara Falcão, e Johanne Lortie (2017), Handbook on Gender and Organizational Change, Turim, International Training Centre of the International Labour Organization (ITCILO).

CITE (2008), Guia de Autoavaliação da Igualdade de Género nas Empresas, Parceria de Desenvolvimento do Projeto "Diálogo Social e Igualdade nas Empresas", Lisboa, CITE.

Cockburn, Cynthia (1983), Brothers. Male Dominance and Technological Change, Londres, Pluto Press.

Coelho, Lina, e Virgínia Ferreira (2018), "Segregação sexual do emprego em Portugal no ultimo quarto de século - agravamento ou abrandamento?", e-cadernos CES, 29, pp. 77-98.

Connell, Raewyn (2006), "Glass ceilings or gendered institutions? Mapping the gender regimes of public sector worksites", Public Administration Review, 66, pp. 792-960.

Conselho da Europa (2003), "Recomendação Rec (2003) 3 do Comité de Ministros aos Estados Membros sobre participação equilibrada de mulheres e homens na tomada de decisão política e pública", [em linha] disponível em: https://rm.coe.int/CoERMPublicCommonSearchServices/DisplayDCTMContent?d ocumentId=0900001680591601 (consultado em 15/04/2019).

Dämmrich, Johanna, e Hans-Peter Blossfeld (2017), “Women's disadvantage in holding supervisory positions: variations among European countries and the role of horizontal gender segregation", Acta Sociologica, 60 (3), pp. 262-282.

EIGE (2019), Decision-Making Database [em linha] disponível em: https://eige.europa.eu/gender-statistics/dgs/indicator/wmidm_bus_bus_wmid_co mp_compbm/bar (consultado em 30/07/2019).

Ely, Robin J., e Debra Meyerson (2000), “Theories of gender in organizations: a new approach to organizational analysis and change", Research in Organizational Behavior, 22, pp. 103-151.

Eriksson-Zetterquist, Ulla, e David Renemark (2016), “Can changes to gender equality be sustained?", Gender, Work \& Organization, 23 (4), pp. 363-378. 
Guerreiro, Maria das Dores, Vanda Lourenço, e Inês Pereira (2006), Boas Práticas de Conciliação entre Vida Profissional e Vida Familiar. Manual para as Empresas, Lisboa, CITE.

Hakim, Catherine (1979), Occupational Segregation. A Comparative Study of the Degree and Pattern of the Differentiation between Men and Women's Work in Britain, the United States and Other Countries, Leicester, Leicester University.

Humbert, Anne L., Elisabeth Kelan, e Kate Clayton-Hathway (2019), “A rights-based approach to board quotas and how hard sanctions work for gender equality", European Journal of Women's Studies, 26 (4), pp. 1-22.

Hymowitz, Carol, e Timothy D. Schellhardt (1986), “Why women can't seem to break the invisible barrier that blocks them from the top jobs", The Wall Street Journal. A Special Report. The Corporate Woman, 207 (57), D1, D4-5.

Kanter, Rosabeth Moss (1977), “Some effects of proportions on group life: skewed sex ratios and responses to token women", American Journal of Sociology, 82 (5), pp. 965-990.

Longarela, Inaki R. (2017), “Explaining vertical gender segregation: a research agenda”, Work, Employment and Society, 31 (5), pp. 861-871.

Martin, Patricia Y., e David Collinson (2002), “Over the pond and across the water: developing the field of gendered organizations", Gender, Work \& Organization, 9 (3), pp. 244-265.

McKay, Alexandra (2017), Strategic Sustainability. Why It Matters to Your Business and How to Make It Happen, Nova Iorque, Routledge.

Monteiro, Rosa, e Virgínia Ferreira (2013), “Planos para a igualdade de género nas organizações: contributos para o desenho e realização dos diagnósticos organizacionais", Sociedade e Trabalho, 43-44-45, pp. 123-136.

Paço, Nuno (2019), Equilíbrio entre Mulheres e Homens nos Órgãos de Governo das Empresas Cotadas em Bolsa. A Influência do Compromisso Estratégico Empresarial, Lisboa, ISEG-ULisboa, dissertação de mestrado em Gestão de Recursos Humanos.

Pernas, Gonçalo, Manuel V. Fernandes, e Maria das Dores Guerreiro, Maria das Dores(2008), Guião para a Implementação de Planos para a Igualdade, Lisboa, CIG.

Rosati, Francesco, e Lourenço G. D. Faria (2019), “Addressing the SDGs in sustainability reports: the relationship with institutional factors", Journal of Cleaner Production, 215, pp. 1312-1326.

Santos, M. Helena, e Lígia Amâncio (2014), “Sobreminorias em profissões marcadas pelo género: consequências e reações”, Análise Social, 212, pp. 700-726.

Seierstad, Cathrina, Gillian Warner-Søderholm, Mariateresa Torchia, e Morten Huse (2017), "Increasing the number of women on boards: the role of actors and processes", Journal of Business Ethics, 141 (2), pp. 289-315.

Steensen, Elmer Fly (2014), "Five types of organizational strategy", Scandinavian Journal of Management, 30 (3), pp. 266-281.

Stevens, Betsy (2009), “Corporate ethical codes as strategic documents: an analysis of success and failure", Electronic Journal of Business Ethics and Organization Studies, 14 (2), pp. 14-20.

Torres, Anália, Paula Campos, Dália Costa, Bernardo Coelho, e Diana Maciel (2018), Igualdade de Género ao Longo da Vida (resumo do estudo), Lisboa, FFMS. 
EQUILÍBRIO ENTRE MULHERES E HOMENS NOS ÓRGÃOS DE GOVERNO DAS EMPRESAS COTADAS EM BOLSA 91

Wall, Karin, e Lígia Amâncio (2007), Família e Género em Portugal e na Europa, Lisboa, Imprensa de Ciências Sociais.

Williams, Christine (1992), "The glass escalator: hidden advantages for men in the 'female' professions", Social Problems, 39 (3), pp. 253-267.

Nuno Paço. Socius - Centro de Investigação em Sociologia Económica e das Organizações / CSG - Investigação em Ciências Sociais E-mail: npaco@iseg.ulisboa.pt

Sara Falcão Casaca. ISEG - Lisbon School of Economics \& Management, Universidade de Lisboa; Socius - Centro de Investigação em Sociologia Económica e das Organizações / CSG - Investigação em Ciências Sociais. E-mail: sarafc@iseg.ulisboa.pt

Receção: 03 de fevereiro de 2020 Aprovação: 14 de abril de 2020 
